OLASOLO, Héctor. "La inseguridad jurídica de los acuerdos de paz a la luz del régimen jurídico internacional de los crímenes de ius cogens y la justicia de transición”.

Polít. crim. Vol. 12, № 23 (Julio 2017), Art. 3, pp. 78-102.

[http://www.politicacriminal.cl/Vol_12/n_23/Vol12N23A3.pdf]

\title{
La inseguridad jurídica de los acuerdos de paz a la luz del régimen jurídico internacional de los crímenes de ius cogens y la justicia de transición
}

\section{Juridical insecurity of the peace agreements under the international legal regime for ius cogens crimes and transitional justice}

\author{
Prof. Dr. Héctor Olasolo Alonso** \\ hectorolasolo@gmail.com
}

\section{Resumen}

Si bien el régimen jurídico de los crímenes de ius cogens es normativamente prevalente sobre aquel de los elementos característicos de la justicia de transición, sería un error desconocer las preocupaciones expresadas por los teóricos de esta última, a la luz de la experiencia acumulada en los últimos veinticinco años. Así mismo, recurrir, como en el caso de Colombia, España o Irlanda del Norte, a las vías de hecho, para a través de una política de hechos consumados intentar "forzar" un cambio en dicho régimen jurídico, es sin duda la estrategia equivocada. Se requiere, por el contrario, alcanzar un mínimo grado de consenso sobre la naturaleza, finalidad, alcance y contenido de los distintos elementos que conforman la justicia de transición, para, sobre esta base, poner fin a este "diálogo de sordos" que ha caracterizado a quienes están llamados a entenderse por tener ámbitos de actuación superpuestos.

Palabras clave: Colombia, crímenes internacionales, derecho internacional penal, ius cogens, justicia transicional.

\footnotetext{
* Licenciado y doctor en Derecho por la Universidad de Salamanca (España); Maestría en Derecho por la Universidad de Columbia (EE.UU). El Prof. Olasolo Alonso es actualmente catedrático de Derecho internacional en la Universidad del Rosario (Colombia), donde dirige su Clínica Jurídica Internacional y el Anuario Ibero-Americano de Derecho Internacional Penal (ANIDIP). Es profesor ad hoc de la Universidad de La Haya para las Ciencias Aplicadas (Holanda) y preside desde 2011 el Instituto Ibero-Americano de la Haya para la Paz, los Derechos Humanos y la Justicia Internacional (Holanda). El Prof. Olasolo Alonso se ha desempeñado también como catedrático de Derecho Internacional Penal en la Universidad de Utrecht (Holanda, 2010-2012), magistrado auxiliar de la Corte Penal Internacional (2004-2010), miembro de la Fiscalía del Tribunal Internacional Penal para la ex Yugoslavia (2002-2004) y asesor jurídico de la delegación española en la Comisión Preparatoria de la Corte Penal Internacional (1999-2002). El autor agradece a Daniela Pedraza Moreno por su inestimable ayuda en la edición de este artículo. Email: hectorolasolo@gmail.com Dirección: Universidad del Rosario. Facultad de Jurisprudencia. Edificio Antiguo Club Jockey. Calle 12C \# 6-25. Bogotá. Colombia.

* El presente trabajo hace parte del proyecto de investigación "principios de armonización entre la función y alcance de la justicia y las demandas surgidas en los procesos políticos de transición" (enero 2017-diciembre 2018), adscrito a la línea de investigación "Crítica al Derecho internacional desde fundamentos filosóficos" del Grupo de Investigación de Derecho Internacional de la Facultad de Jurisprudencia de la Universidad del Rosario (Colombia). El proyecto es financiado por la Dirección de Investigación e Innovación de la Universidad del Rosario.
} 
OLASOLO, Héctor. "La inseguridad jurídica de los acuerdos de paz a la luz del régimen jurídico internacional de los crímenes de ius cogens y la justicia de transición”.

\begin{abstract}
While the international legal regime of ius cogens crimes is normatively prevalent over the legal recognition of the main elements of transitional justice, it would be a mistake to reject the concerns expressed by transitional justice theorists in light of the experience gained in the last twenty-five years. Similarly, hoping to force a change in its content through a policy of fait acompli, as in the situations in Colombia, Northern Ireland and Spain, is certainly the wrong strategy. What is needed now is to reach some degree of consensus on the nature, goals, scope and content of the different elements of transitional justice, and, on this basis, to make an effort to end this "dialogue of the deaf" that, for more than two decades, has characterized the relationship between those interacting on overlapping fields of application.
\end{abstract}

Key words: Colombia, international crimes, international criminal law, ius cogens, transitional justice.

\title{
1. Introducción.
}

El pasado 2 de octubre de 2016, el resultado del referéndum convocado por el Gobierno de Colombia para ratificar el acuerdo de paz firmado en Cartagena el 26 de septiembre ${ }^{1}$, en presencia del Secretario General de las Naciones Unidas, con las Fuerzas Armadas Revolucionarias de Colombia - Ejército del Pueblo (FARC-EP), rechazaba por un estrecho margen, y de manera imprevista, su contenido. Días después llegaban las primeras propuestas de renegociación del acuerdo por parte de los partidarios del "no", iniciándose una serie de rondas de consultas entre estos últimos y el Gobierno por una parte, y el propio Gobierno y las FARC-EP por otra. El 12 de noviembre de 2016, el gobierno de Colombia firmaba un nuevo acuerdo de paz con las FARC en La Habana, que era rechazado al día siguiente por los principales valedores del "no" en el referéndum del 2 de octubre. Es en el marco de este contexto, en el que prima la incertidumbre, en el que se realiza la presente reflexión sobre la inseguridad jurídica a la que parecen estar abocados los acuerdos de paz que puedan eventualmente surgir de los procesos de negociación actualmente en curso (el 1 de noviembre de 2016 se iniciaron las negociaciones de paz entre el Gobierno de Colombia y la otra fuerza insurgente históricamente operativa en Colombia, el Ejército de Liberación Nacional (ELN)), como consecuencia de la ausencia de armonización entre el consolidado régimen jurídico internacional de los crímenes de ius cogens y las exigencias derivadas de la necesidad de articular procesos políticos de transición que permitan superar las situaciones en que se cometen los mismos.

\section{Planteamiento del problema.}

Desde el resurgimiento de la aplicación el Derecho internacional penal a nivel nacional e internacional en la década de 1990, y el simultáneo desarrollo jurisprudencial de las

\footnotetext{
${ }^{1}$ GOBIERNO DE COLOMBIA Y FARC-EP, Acuerdo Final para la Terminación del Conflicto de una Paz Estable y Duradera, alcanzado el 24 de agosto de 2016, y firmado el 26 de septiembre de 2016. Disponible en: https://www.mesadeconversaciones.com.co/sites/default/files/acuerdo-final-1473286288.pdf [visitado el 15/09/2016].
} 
Polít. crim. Vol. 12, № 23 (Julio 2017), Art. 3, pp. 78-102.

[http://www.politicacriminal.cl/Vol_12/n_23/Vol12N23A3.pdf]

obligaciones generales de los Estados derivadas de las violaciones graves del Derecho internacional de los derechos humanos y el Derecho internacional humanitario, se ha puesto de relieve que la reafirmación, por primera vez desde el inicio de la guerra fría, de los deberes de los Estados de investigar, enjuiciar, sancionar penalmente y reparar integralmente a las víctimas, y los correspondientes derechos de estas últimas a la verdad, la justicia y reparación, en relación con el genocidio, los crímenes de lesa humanidad y los crímenes de guerra, está teniendo un impacto significativo en aquellos procesos políticos de transición que enfrentan las tradicionales demandas de exención de responsabilidad por parte de los principales actores involucrados en los mismos ${ }^{2}$.

Ante esta situación, algunos teóricos de la justicia de transición, entre los cuales Elster ${ }^{3}$ es el más representativo, niegan que los procesos penales por crímenes de ius $\operatorname{cogens}^{4}$ tengan una naturaleza normativo-vinculante, puesto que, en su opinión, todos y cada uno de los mecanismos que pueden utilizarse en los procesos políticos de transición para superar situaciones de violaciones de derechos humanos a gran escala tienen una naturaleza meramente descriptiva, cuya función es servir de guía no vinculante para el diseño del componente justicia dentro de los mismos. Como Vacas Fernández subraya, de acuerdo con esta interpretación, los términos en que ha de realizarse una determinada transición dependen exclusivamente de lo acordado por las partes negociadoras, sin que el Derecho internacional imponga estándares de obligatorio cumplimiento que deban ser respetados sin que puedan ser objeto de negociación ${ }^{5}$.

En sintonía con esta posición se encuentra la preocupación de Nagy frente a las tendencias de la sociedad internacional a imponer soluciones monolíticas (one size for all), tecnocráticas y descontextualizadas ${ }^{6}$. En la misma dirección se sitúa también el planteamiento de Corradetti, Eisikovits \& Rotondi $^{7}$, quienes, sobre la base de las experiencias políticas, sociológicas y prácticas de las transiciones en España, Irlanda del Norte y Mozambique, subrayan que existen al menos tres tipos de situaciones en las que resulta problemático afirmar el carácter vinculante de las medidas de verdad y

${ }^{2}$ OLASOLO, Héctor; MATEUS, Andrea y CONTRERAS, Andrés, "La naturaleza imperativa del principio "no hay paz sin justicia" respecto a los máximos responsables del fenómeno de la lesa humanidad y sus consecuencias para el ámbito de actuación de la llamada "justicia de transición"”, Boletín Mexicano de Derecho Comparado, ${ }^{\circ} 145$ (2016), pp. 136-139.

${ }^{3}$ ELSTER, Jon, Closing the Books: Transitional Justice in Historical Perspective, Cambridge: Cambridge University Press, 2004.

${ }^{4}$ A los efectos del presente trabajo, cuando nos referimos a crímenes de ius cogens, nos estamos refiriendo a aquellos a aquellos crímenes internacionales sobre los que los tribunales internacionales penales creados a partir de la década de 1990 tienen jurisdicción: genocidio, crímenes de lesa humanidad y crímenes de guerra.

${ }^{5}$ VACAS FERNÁNDEZ, Félix, "Los Derechos de las Víctimas y la Negociación: El Caso de Colombia”, en: DÍAZ BARRADO, Castor; FERNÁNDEZ LIESA, Carlos y RODRÍGUEZ-VILLASANTE, José Luis (Dirs.), Derecho Internacional Humanitario y Derechos Humanos: Reflexiones Sobre el Caso de Colombia, Madrid: Civitas, 2013, p. 575. En el mismo sentido, TAMARIT, Josep Maria, "Los límites de la justicia transicional penal: la experiencia del caso español", Política criminal, vol. 7, n 13 (julio 2012), art. 2, pp. 74-93.

${ }^{6}$ NAGY, Rosemary, "Transitional Justice as Global Project: Critical Reflections", en: BUCHANAN, Ruth y ZUMBASEN, Peer (Eds.), Law in Transition. Human Rights, Development and Transitional Justice, Oxford: Hart Publishing, 2014, p. 215.

${ }^{7}$ CORRADETTI, Claudio; EISIKOVITS, Nir y ROTONDI, Jack, "Introduction", en: CORRADETTI, Claudio; EISIKOVITS, Nir; ROTONDI, Jack (Eds.), Theorizing Transitional Justice, Surrey: Ashgate, 2014, p. 5. 
OLASOLO, Héctor. "La inseguridad jurídica de los acuerdos de paz a la luz del régimen jurídico internacional de los crímenes de ius cogens y la justicia de transición".

responsabilidad civil y penal: (i) sociedades de post-conflicto que muestran una ambivalencia cultural hacia las políticas de declaración y realización de las responsabilidades por abusos del pasado (Mozambique); (ii) sociedades en las que existe una compleja división de culpas entre las distintas partes (Irlanda del Norte); y (iii) sociedades en las que la insistencia en actividades de búsqueda de la verdad y realización de las responsabilidades por abusos del pasado generan un riesgo serio de reactivar la violencia o el conflicto (España en la segunda mitad de la década de 1970 y primera mitad de 1980).

Frente a estos autores, Teitel afirma la naturaleza normativo-vinculante, conforme al Derecho internacional, de los distintos elementos que conforman la justicia de transición, puesto que el olvido del pasado sin el análisis de lo ocurrido y la determinación de las responsabilidades derivadas del mismo, impiden el desarrollo de auténticas transiciones y generan una mayor división entre víctimas y victimarios ${ }^{8}$. Sin embargo, como Clamp y Doak señalan, incluso para este segundo grupo de autores es necesario buscar un compromiso entre el contenido de las demandas de exención de responsabilidad civil y penal, y el actual régimen jurídico de los crímenes de ius cogens ${ }^{9}$.

Es en este contexto en el que algunos países como Colombia han diseñado entre 2005 y 2016 hasta tres modelos distintos de justicia de transición. Así, la Ley 975 de 2005 de Justicia y Paz, sólo aplicable a los grupos armados al margen de la ley (principalmente, pero no exclusivamente, a los grupos paramilitares), introdujo un modelo que giraba principalmente en torno a las actuaciones judiciales para la determinación de la verdad (con el aporte complementario de la Comisión Nacional de Reparación y Reconciliación), la realización de responsabilidades penales y civiles, y la provisión de reparaciones a las victimas (si bien los subsiguientes decretos gubernamentales y la Ley 1448 de 2011 de Víctimas y Restitución de Tierras, introdujeron importantes componentes administrativos en materia de reparación). Desde una perspectiva estrictamente penal, este modelo se caracterizaba por el establecimiento de penas alternativas de reclusión de 5 a 8 años, más cuatro años adicionales de libertad condicional, para los desmovilizados condenados que cumplieran con los requisitos recogidos en la Ley $975^{10}$.

Posteriormente, el denominado "Marco Jurídico para la Paz", aprobado a través del acto legislativo 01 de 2012, introdujo dos artículos transitorios (66 bis y 67 bis) en la Constitución Política de Colombia, aplicables tanto a los agentes del Estado como a los miembros de grupos armados al margen de la ley, estableciendo toda una "estrategia de justicia transicional" de naturaleza eminentemente administrativa, donde se preveía una intervención muy limitada de los tribunales de justicia. Los elementos centrales de este modelo administrativo de justicia de transición consistían en la creación de una Comisión de la Verdad y un régimen de reparaciones en vía administrativa, el establecimiento de criterios de selección de casos que facultaban al Congreso de la República a prohibir al

\footnotetext{
${ }^{8}$ TEITEL, Ruti, Transitional Justice, Oxford: Oxford University Press, 2000.

${ }^{9}$ CLAMP, Kerry y DOAK, Jonathan, "More than Words: Restorative Justice Concepts in Transitional Justice Settings", International Criminal Law Review, vol. 12, n 3 (2012), pp. 330-360

${ }^{10}$ Ley 975 de Justicia y Paz, Diario Oficial de la República de Colombia, No. 45.980 de 25 de julio de 2005 artículos 10,11 y 29.
} 
Polít. crim. Vol. 12, № 23 (Julio 2017), Art. 3, pp. 78-102.

[http://www.politicacriminal.cl/Vol_12/n_23/Vol12N23A3.pdf]

Fiscal General de la Nación el ejercicio de la acción penal contra todos aquellos que no pudieran ser calificados como máximos responsables de genocidio, crímenes de lesa humanidad o crímenes de guerra, la atribución al Fiscal General de la facultad para que estableciera criterios de priorización en el tratamiento de los casos seleccionados, la previsión de penas alternativas de reclusión de duración incierta, la aplicación de regímenes especiales de ejecución de las penas impuestas en los casos seleccionados (permitiendo originalmente incluso la suspensión de la ejecución de las penas, medida que posteriormente sería declarada inexequible por la Corte Constitucional), y el establecimiento de un sistema de sanciones extrajudiciales para los casos no seleccionados.

El denominado Sistema Integral de Verdad, Justicia, Reparación y No Repetición, previsto en acuerdo firmado el 26 de septiembre de 2016 entre el Gobierno de Colombia y las FARC-EP, y rechazado en el referéndum del 2 de octubre, puede catalogarse como un modelo mixto en cuanto que combina la creación de una Jurisdicción Especial para la Paz, con el establecimiento de toda una serie de instituciones y medidas de carácter administrativo como son la Comisión para el Esclarecimiento de la Verdad, la Convivencia y la No Repetición (cuyo mandato se encuentra limitado a un máximo de tres años), la Unidad Especial para la Búsqueda de Personas dadas por Desaparecidas en el contexto y en razón del conflicto, y las medidas de reparación, en gran medida, de naturaleza colectiva. Desde una perspectiva penal, y a diferencia de la Ley de Justicia y Paz, este modelo tiene como elementos esenciales la limitación de las penas impuestas (máximo de 20 años de reclusión) a quienes no cumplen con los requisitos exigidos para la imposición de penas alternativas, y la provisión para quienes sí cumplen con dichos requisitos de un régimen de penas alternativas que, como regla general, excluyen la reclusión. Así, la principal pena alternativa por condenas por genocidio, crímenes de lesa humanidad y crímenes de guerra, consiste en la restricción de derechos de 5 a 8 años (por ejemplo, la realización de trabajos comunitarios), o, en caso de que dichos delitos sean específicamente calificados como "muy graves" en la prohibición de salir de una determinada región geográfica (por ejemplo, un municipio) por ese mismo espacio de tiempo. Sólo en el caso de que el reconocimiento de responsabilidad llegue una vez iniciado el juicio oral y antes de la emisión de sentencia se prevé una pena alternativa de reclusión de 5 a 8 años. El nuevo acuerdo alcanzado el 12 de noviembre de 2016 entre el gobierno de Colombia y las FARC, y rechazado al día siguiente por insuficiente por los principales defensores del "no" en el referéndum del 2 de octubre, asume el modelo de penas previsto en el acuerdo de 26 de septiembre, limitando la extensión de las regiones geográficas a las que verán confinados los condenados por aquellos crímenes de ius cogens que sean considerados como "muy graves" a la extensión de "Zonas Veredales Transitorias de Normalización", e incluyendo a su vez una reglamentación más detallada del régimen de cumplimiento este tipo de pena alternativa ${ }^{11}$.

\footnotetext{
${ }^{11}$ GOBIERNO DE COLOMBIA Y FARC-EP, Acuerdo de 26 de septiembre de 2016, cit. nota ${ }^{\circ} 1$, pp. 147148. Vid. también GOBIERNO DE COLOMBIA Y FARC-EP, Acuerdo Final para la Terminación del Conflicto de una Paz Estable y Duradera, firmado el 12 de noviembre de 2015. Disponible en: http://www.altocomisionadoparalapaz.gov.co/procesos-y-conversaciones/Paginas/Texto-completo-delAcuerdo-Final-para-la-Terminacion-del-conflicto.aspx, pp. 165-166. Vid. así mismo a este respecto, GIL, Alicia, "El tratamiento jurídico de los crímenes cometidos en el conflicto armado colombiano. La problemática jurídica en el marco de la dicotomía paz-justicia”, en: ALDA MEJÍAS, Sonia y S. FERREIRA DE SOUSA, Susana, Semana Iberoamericana. Madrid: IUGM, 2016.
} 
OLASOLO, Héctor. "La inseguridad jurídica de los acuerdos de paz a la luz del régimen jurídico internacional de los crímenes de ius cogens y la justicia de transición”.

De esta manera, Colombia se ha convertido en un auténtico laboratorio para la búsqueda del tipo de compromiso al que Clamp y Doak se refieren en su trabajo, a través de diversas fórmulas cuya conformidad con el ordenamiento jurídico internacional vigente ha sido siempre muy cuestionable. Ante esta situación, las secciones 2 y 3 del presente trabajo analizan el consolidado régimen jurídico internacional de los crímenes de ius cogens, y lo contrastan con la ausencia de reconocimiento en el Derecho internacional de los diversos componentes de la justicia de transición, debido a la falta de consenso sobre la naturaleza, finalidad, alcance y contenido de los mismos. A continuación, la sección 4 analiza la inidoneidad de las vías de hecho para modificar dicho marco normativo, y la inseguridad jurídica a la que parecen abocados dichos esfuerzos. Finalmente, en la sección 5 se subraya la necesidad de que los teóricos y profesionales de la justicia de transición hagan un esfuerzo para alcanzar un mínimo grado de consenso como pre-requisito para que se pueda llevar a cabo una revisión comprehensiva del actual marco normativo internacional con el fin de que integre, en la medida de lo posible, los elementos esenciales de la regulación jurídica de los crímenes de ius cogens, con la necesidad de articular procesos políticos de transición que permitan superar las situaciones en que se cometen los mismos.

\section{El marco normativo de los crímenes de ius cogens en el Derecho internacional.}

La jurisprudencia de la Corte Internacional de Justicia considera que la prohibición del genocidio y las normas fundamentales del Derecho internacional de los derechos humanos (DIDH) y del Derecho internacional humanitario (DIH) forman parte de aquel conjunto de normas, denominado derecho imperativo o ius cogens, que tienen un mayor rango jerárquico en el Derecho internacional, y frente a las cuales no es posible alegar la existencia de normas convencionales, consuetudinarias o principios generales del derecho que no hayan alcanzado dicho rango normativo ${ }^{12}$.

La Corte Internacional de Justicia también ha subrayado que el genocidio y las infracciones graves a las normas fundamentales del DIDH (crímenes de lesa humanidad) y del DIH (crímenes de guerra) forman parte de la categoría de crímenes de ius cogens ${ }^{13}$. En el mismo sentido, la jurisprudencia de los tribunales internacionales penales, en particular el Tribunal Internacional para la ex Yugoslavia ${ }^{14}$ y la Corte Especial para Sierra Leona ${ }^{15}$, ha hecho

\footnotetext{
${ }^{12}$ Al respecto ver: Sentencia Barcelona Traction Light and Power Company Limited. Sentencia, s.l.: Corte Internacional de Justicia, 5 de febrero de 1970; Sentencia Military and Paramilitary Activities in and against Nicaragua, s.l.: Corte Internacional de Justicia, 27 de junio de 1986; Sentencia Caso concerniente a Timor del Este, Portugal c. Australia, s.1.: Corte Internacional de Justicia, 30 de junio de 1995; Sentencia caso Yerodia, República Democrática del Congo c. Belgica, Corte Internacional De Justicia, 14 de febrero de 2002; Sentencia caso relativo a las Inmunidades Jurisdiccionales del Estado, Alemania c. Italia; Grecia interviniente, Corte Internacional de Justicia, 3 de febrero de 2012.

${ }_{13} \mathrm{Al}$ respecto ver: los casos mencionados en la nota anterior.

14 Ver: Secretario General de las Naciones Unidas, Doc. S/25704, 3 de mayo de 1993, Párr. 34, citado por: Sentencia de apelación. IT-94-1-A, Prosecutor v. Dusko Tadic, Tribunal Internacional Penal para la ex Yugoslavia, 15 de julio de 1999, Párr. 296; Sentencia Sala de Primera Instancia. IT-95-16-T, Prosecutor v. Zoran Kupreskic. Mirjan Kupreskic. Vlatko Kupreskic and Drogan Papic, Tribunal Internacional Penal para la ex Yugoslavia 14 de enero de 2000., Párr. 520. Además, en relación con la tortura como crimen de lesa humanidad y como crimen de guerra, véase Sentencia Sala de Primera Instancia. IT-96-21-T, Prosecutor v. Zejnil Delalic. Zdravko Mucic. Hazim Delic and Esad Landzo, Tribunal Internacional Penal para la ex Yugoslavia 16 de noviembre de 1998, Párr. 454; y Sentencia Sala de Primera Instancia. IT-96-23-T \& IT-96-
} 


\section{Polít. crim. Vol. 12, No 23 (Julio 2017), Art. 3, pp. 78-102. [http://www.politicacriminal.cl/Vol_12/n_23/Vol12N23A3.pdf]}

especial énfasis en el carácter de ius cogens de las normas que atribuyen responsabilidad internacional penal a quienes incurren en cualquiera de estas tres categorías de delitos.

A este respecto, la Corte Interamericana de Derechos Humanos ha sido incluso más vocal al afirmar en los casos Almonacid Arellano et al ${ }^{16}$, Penal Miguel Castro Castro ${ }^{17}$ y Universidad La Cantuta ${ }^{18}$, el carácter de ius cogens de la atribución de responsabilidad internacional penal a quienes incurren en crímenes de lesa humanidad, así como de la obligación de los Estados, en cuyo territorio o bajo cuya jurisdicción se han cometido, de realizar dicha responsabilidad mediante la investigación de los hechos, el enjuiciamiento de los presuntos responsables y la sanción de quienes sean condenados ${ }^{19}$. Estos últimos casos han subrayado también la naturaleza imperativa de la imprescriptibilidad de los crímenes de lesa humanidad y de la prohibición de leyes de amnistía frente a la responsabilidad internacional penal derivada de su comisión. Sin embargo, la Corte Internacional de Justicia y el Tribunal Europeo de Derechos Humanos han guardado silencio sobre la inclusión en el derecho imperativo de estos últimos elementos del régimen jurídico de los crímenes de ius cogens $^{20}$.

23/1-T, Prosecutor v. Dragoljub Kunarac. Radomir Kovac and Zoran Vokovic, Tribunal Internacional Penal para la ex Yugoslavia, 22 de febrero de 2001, Párr. 466.; y Sentencia Sala de Primera Instancia. IT-95-/7/1-T, Prosecutor v. Anto Furundzija, Tribunal Internacional Penal para la ex Yugoslavia, 10 de diciembre de 1998, Párr. 153-157.

${ }^{15}$ Ver: Appeals Chamber Decision on Preliminary motion on the invalidity of the agreement between the United Nations and the Government of Sierra Leone on the establishment of the Special Court, SCSL-200415-AR72 (E), Prosecutor v. Augustine Gbao (2004): Corte Especial para Sierra Leona, 25 de mayo de 2004, párr. 9.

${ }^{16}$ Sentencia de excepciones preliminares, fondo, reparaciones y costas, Serie C. Núm. 154, Almonacid Arellano y otros c. Chile, Corte Interamericana de Derechos Humanos 26 de septiembre de 2006, párr. 114.

${ }^{17}$ Sentencia de fondo, reparaciones y costas Penal Miguel Castro Castro c. Perú, Corte Interamericana de Derechos Humanos, 25 de noviembre de 2006, párr. 402 y 404.

${ }^{18}$ Sentencia de fondo, reparaciones y costas, Serie C. Núm. 162, La Cantuta c. Peru, Corte Interamericana de Derechos Humanos, 29 de noviembre de 2006, párr. 168 y 225.

${ }^{19}$ Sentencia de excepciones preliminares, fondo, reparaciones y costas, Serie C. Núm. 154, Almonacid Arellano y otros c. Chile, Corte Interamericana de Derechos Humanos 26 de septiembre de 2006, Serie C. Núm. 154, Párr. 114; Corte Interamericana de Derechos Humanos, Sentencia de fondo, reparaciones y costas Penal Miguel Castro Castro c. Perú, Corte Interamericana de Derechos Humanos, 25 de noviembre de 2006, párr. 402 y 404; Sentencia de fondo, reparaciones y costas, Serie C. Núm. 162, La Cantuta c. Peru, Corte Interamericana de Derechos Humanos, 29 de noviembre de 2006, Serie C. Núm. 162. Párr. 168 y 225.

${ }^{20}$ En su decisión de fondo en el caso República Democrática del Congo c. Bélgica, la Corte Internacional de Justicia acogió la posición de la RDC, que sostenía que al ser el acusado de la comisión de crímenes de lesa humanidad y de crímenes de guerra su Ministro de Asuntos Exteriores, se encontraba amparado por la inmunidad personal que, por razón del cargo ejercido, reconoce el Derecho internacional consuetudinario, con independencia de la naturaleza de los delitos imputados. La Corte Internacional de Justicia alcanzó esta conclusión sobre la base de que la naturaleza procesal del principio de inmunidad de jurisdicción del Estado no puede entrar nunca en conflicto con la naturaleza sustantiva de la regulación que proscribe los crímenes internacionales de ius cogens. Ver Sentencia caso Yerodia, República Democrática del Congo c. Belgica, Corte Internacional De Justicia, 14 de febrero de 2002.Posteriormente, en el caso Alemania c. Italia, la Corte Internacional de Justicia aceptó las alegaciones de Alemania a favor de su inmunidad de jurisdicción frente a los procesos por daños civiles que se estaban llevando a cabo en su contra en Italia, con el fin de declarar su responsabilidad estatal por la comisión de crímenes internacionales atroces durante la segunda guerra mundial. Ver Sentencia caso relativo a las Inmunidades Jurisdiccionales del Estado, Alemania c. Italia; Grecia interviniente, Corte Internacional De Justicia, 3 de febrero de 2012. Por su parte, el Tribunal Europeo de Derechos Humanos, en el caso Aladsani c. Reino Unido (sentencia de 21 de noviembre de 2002), después de 
OLASOLO, Héctor. "La inseguridad jurídica de los acuerdos de paz a la luz del régimen jurídico internacional de los crímenes de ius cogens y la justicia de transición".

La ausencia de consenso sobre la naturaleza de derecho imperativo de algunos de los elementos característicos del régimen jurídico de los crímenes de ius cogens, no significa que los mismos no formen parte del ordenamiento jurídico internacional ${ }^{21}$. En este sentido, el Comité de Derechos Humanos, en su Observación General 31, nos recuerda que la obligación de garantía impuesta a los Estados parte en el artículo 2(1) del Pacto Internacional de Derechos Civiles y Políticos, (PIDCP), hace que se encuentren obligados a investigar, enjuiciar y castigar penalmente todas la violaciones del PIDCP cometidas bajo su jurisdicción que sean constitutivas de genocidio, crímenes de lesa humanidad y crímenes de guerra $^{22}$, lo que significa también la prohibición de eximir de responsabilidad a sus presuntos responsables como parte de los procesos políticos de transición ${ }^{23}$. Asi mismo, el Preámbulo del Estatuto de la Corte Penal Internacional subraya expresamente que "es deber de todo Estado ejercer su jurisdicción penal contra los responsables de crímenes internacionales" 24 .

Este régimen jurídico es resultado de entender que si algo caracteriza a los crímenes de ius cogens, es que las conductas prohibidas constituyen una suma de atrocidades ${ }^{25}$, fruto de la contaminación cancerígena de la acción política ${ }^{26}$, pues de otra manera es difícilmente

aceptar la jurisprudencia del Tribunal Internacional Penal para la ex Yugoslavia sobre la naturaleza imperativa de la prohibición de la tortura, y una vez analizadas las decisiones de los tribunales británicos en el caso del ex-dictador chileno Augusto Pinochet y las enmiendas a la Foreign Sovereign Immunities Act (FSIA) de los Estados Unidos, afirmó que el Derecho internacional vigente en 2001 no recogía ninguna excepción a la inmunidad de jurisdicción para casos de graves violaciones a los derechos humanos. Esta posición se ha visto confirmada en 2014 con el fallo del caso Jones et al. c. Reino Unido (sentencia de 14 de enero de 2014), en el que el Tribunal EDH reitera que no existe ninguna norma de Derecho internacional consuetudinario que exceptúe la inmunidad de jurisdicción frente a hechos constitutivos de violaciones al ius cogens. De hecho, para el Tribunal EDH, no existe ningún conflicto entre las normas que regulan la inmunidad de jurisdicción y aquellas que recogen la prohibición de la tortura como norma de ius cogens, porque las primeras tienen una naturaleza meramente procesal en relaciónB con el ejercicio de la jurisdicción para investigar y sancionar los actos de tortura, mientras que la prohibición de la tortura tiene un carácter sustantivo al establecer una prohibición de carácter imperativo en el Derecho internacional. Véase a este respecto, OLASOLO, Héctor, MARTÍNEZ, Júan y RODRÍGUEZ, Ana María, "La inmunidad de jurisdicción penal por crímenes internacionales de los Jefes de Estado, los Jefes de Gobierno y los Ministros de Asuntos Exteriores", Revista Chilena de Derecho, vol. 43, $\mathrm{n}^{\circ} 1$ (2016), pp. 251-281.

${ }^{21}$ OLASOLO, La naturaleza imperativa, cit. nota ${ }^{\circ}$ 2, pp. 167-168. Para una interpretación contraria, vid. ACOSTA, Diego; BUCHAN, Russell y UREÑA, René, "Beyond Justice, Beyond Peace? Colombia, the Interests of Justice, and the Limits of International Criminal Law", Criminal Law Forum, Vol. 26, n 2 (2015), pp. 291-318; MALARINO, Ezequiel, "Transición, derecho penal y amnistía. Reflexiones sobre la utilización del derecho penal en procesos de transición", Revista de Derecho penal y Criminología, no 9 (2003), pp. 205-222; y MALLINDER, Louise, Amnesty human rights and political transitions: bridging the peace and justice divide, Oxford: Hart, 2008.

${ }^{22}$ El Comité de Derechos Humanos no limita su afirmación a estas tres categorías de delitos, sino que la extiende a todos los "crímenes internacionales". Véase COMITÉ DE DERECHOS HUMANOS DE LAS NACIONES UNIDAS, General Comment 31, Nature of General Obligation on States Parties to the Covenant, Doc. CCPR/C/21/Rev.1/Add.13, 29 de marzo de 2004, párr. 18.

${ }^{23}$ COMITÉ DE DERECHOS HUMANOS, Doc. CCPR/C/21/Rev.1/Add.13, cit. nota n ${ }^{\circ}$ 21, párr. 18.

${ }^{24}$ CORTE PENAL INTERNACIONAL, Preámbulo del Estatuto de Roma, 17 de julio de 1998, párr. 5.

${ }^{25}$ OSIEL, Mark, "Why Prosecute? Critics of Punishment for Mass Atrocity", Human Rights Quarterly, vol. 22 (2000), p. 121.

${ }^{26}$ LUBAN, David, “A Theory of Crimes against Humanity”, Yale International Law Journal, vol. 29 (2004), p. 90. De acuerdo a Luban, "precisamente debido a que no podemos vivir sin política, es que existimos bajo la 
Polít. crim. Vol. 12, № 23 (Julio 2017), Art. 3, pp. 78-102.

[http://www.politicacriminal.cl/Vol_12/n_23/Vol12N23A3.pdf]

explicable el diseño y puesta en marcha de campañas de violencia dirigidas a destruir un grupo nacional, étnico, racial o religioso (genocidio), a atacar a la población civil de manera sistemática o a gran escala (crímenes de lesa humanidad), o a afectar a aquellas personas y objetos que se encuentran protegidos en una situación de conflicto armado por encontrarse en posición de particular vulnerabilidad (crímenes de guerra). Esto significa además que allí donde se cometen este tipo de crímenes será, antes o después, necesario que se lleven a cabo procesos políticos de transición que pongan fin a regímenes caracterizados por la comisión sistemática o generalizada de graves violaciones de derechos humanos, o que faciliten el tránsito de situaciones de conflicto armado a situaciones de paz. En todos ellos, de acuerdo con la regulación vigente en el Derecho internacional, será normativamente obligatorio investigar, enjuiciar y castigar a los responsables de dichos crímenes a través de procesos penales desarrollados ante tribunales nacionales o internacionales, así como reparar integralmente a las víctimas ${ }^{27}$.

Es en este contexto que el Comité de Derechos Humanos abordó en 2015 los informes relativos a España e Irlanda de Norte, dos de los tres tipos de situaciones en las que, según Corradetti, Eisikovits \& Rotondi, resulta problemático afirmar el carácter vinculante de las medidas de verdad y responsabilidad civil y penal en los procesos políticos de transición ${ }^{28}$. Analizándolo desde una perspectiva estrictamente normativa, a la luz del régimen jurídico internacional vigente de los crímenes de ius cogens, el Comité de Derechos Humanos no podría estar en mayor desacuerdo con estos autores. Así, en su informe de 14 de agosto de 2015 con respecto a España, el Comité de Derechos Humanos expresó su preocupación por: (i) la posición del Estado parte de mantener en vigor la Ley de Amnistía de 1977, que impide la investigación de las violaciones de los derechos humanos del pasado, en particular los delitos de tortura, desapariciones forzadas y ejecuciones sumarias; (ii) las lagunas y deficiencias en la regulación de los procedimientos de búsqueda, exhumación e identificación de personas desaparecidas, y en particular el hecho de que su localización e identificación se dejan a cargo de la iniciativa de los familiares, con las desigualdades ello supone para las víctimas dependiendo del lugar en que se encuentren; y (iii) las dificultades existentes para el acceso a los archivos, especialmente los militares ${ }^{29}$.

A raíz de lo anterior, el Comité de Derechos Humanos ${ }^{30}$ reiteró su recomendación para que España derogue la Ley de Amnistía o la enmiende para hacerla plenamente compatible con las disposiciones del PIDCP. Así mismo, solicitó a España que impulse activamente las investigaciones respecto de todas las violaciones a los derechos humanos del pasado, debiendo velar por que en estas investigaciones se identifique a los responsables, se los enjuicie y se les impongan sanciones apropiadas, proporcionales a la gravedad de los

amenaza permanente de que la política devendrá cancerígena y que las instituciones indispensables de la vida política organizada nos destruirán" (traducción del autor).

27 OLASOLO, Héctor, "El principio 'no hay paz sin justicia' como principio rector del tratamiento del fenómeno de la lesa humanidad por el Derecho internacional y su impacto en los procesos de paz: particular atención al caso colombiano", en: OLASOLO, Héctor, Introducción al Derecho internacional penal, Valencia: Tirant lo Blanch. Universidad del Rosario \& IIH, diciembre de 2014, pp. 51-77.

${ }^{28}$ CORRADETTI/EISIKOVITS/ROTONDI, "Introduction", cit. nota ${ }^{\circ} 7$, p. 5.

${ }^{29}$ COMITÉ DE DERECHOS HUMANOS DE LAS NACIONES UNIDAS, Concluding observations on the sixth periodic report of Spain, CCPR/C/ESP/CO/6, 14 de Agosto de 2015, párr. 21.

${ }^{30}$ COMITÉ DE DERECHOS HUMANOS, CCPR/C/ESP/CO/6, cit. nota n 29, párr. 21. 
OLASOLO, Héctor. "La inseguridad jurídica de los acuerdos de paz a la luz del régimen jurídico internacional de los crímenes de ius cogens y la justicia de transición”.

crímenes y se repare a las víctimas. Además, el Comité de Derechos Humanos, urgió a España para que revisase su legislación relativa a la búsqueda, exhumación e identificación de las personas desaparecidas, estableciera un marco normativo a nivel nacional para sus archivos y permitiera la apertura de los mismos sobre la base de criterios claros y públicos, de conformidad con los derechos recogidos en el PIDCP ${ }^{31}$.

Del mismo modo, en su informe de 17 de agosto de 2015 en relación con Gran Bretaña e Irlanda del Norte, el propio Comité de Derechos Humanos ${ }^{32}$ subrayó su preocupación por el lento avance del proceso de promoción de rendición de cuentas en relación con el conflicto de Irlanda del Norte y por la inexistencia de un marco general para atender a las violaciones graves de los derechos humanos relacionadas con el conflicto. ${ }^{33}$ Como resultado recomendó a Irlanda del Norte: (i) velar, con carácter especialmente urgente, por que se realicen investigaciones independientes, imparciales, rápidas y eficaces, incluidas las propuestas en el marco del Acuerdo de Stormont House, para asegurar que se publique una versión completa, transparente y creíble de las circunstancias que rodearon los sucesos de Irlanda del Norte con el fin de identificar, enjuiciar y sancionar a los autores de violaciones de los derechos humanos, en particular el derecho a la vida, y proporcionar recursos adecuados a las víctimas; (ii) promover la creación de la Dependencia de Investigaciones Históricas, de manera que comience a trabajar a pleno rendimiento tan pronto como sea posible, garantizando su independencia por ley, proporcionándole una financiación adecuada y suficiente para que pueda investigar de manera efectiva todos los casos pendientes, y asegurando que pueda acceder a toda la documentación y material pertinentes para sus investigaciones; (iii) asegurar que la Oficina de Investigación Histórica y el Servicio Forense de Irlanda del Norte cuenten con recursos adecuados y estén en condiciones de examinar eficazmente los casos pendientes del pasado; y (iv) reconsiderar su posición sobre las amplias facultades del poder ejecutivo para impedir su publicación ${ }^{34}$.

\section{La ausencia de reconocimiento de los distintos componentes de la justicia de transición en el Derecho internacional.}

A diferencia del consolidado marco normativo internacional de los crímenes de ius cogens, ni el Derecho internacional general, ni el convencional, regulan los distintos elementos que conforman la justicia de transición. Tan solo una definición general de esta última aparece recogida en una norma no vinculante de soft law, como es el informe del Secretario General

\footnotetext{
31 En este sentido, el Comité de Derechos Humanos urgió a España a implementar las recomendaciones realizadas en 2013 por el Grupo de Trabajo sobre Desapariciones Forzadas e Involuntarias de las Naciones Unidas. Véase COMITÉ DE DERECHOS HUMANOS, CCPR/C/ESP/CO/6, cit. nota n 29, párr. 22.

${ }^{32}$ COMITÉ DE DERECHOS HUMANOS DE LAS NACIONES UNIDAS, Concluding observations on the seventh periodic report of the United Kingdom of Great Britain and Northern Ireland, CCPR/C/GBR/CO/7, 17 de Agosto de 2015, párr. 8.

${ }^{33} \mathrm{El}$ Comité de Derechos Humanos ya había expresado este tipo de preocupaciones en su informe anterior sobre Gran Bretaña e Irlanda del Norte. Véase a este respecto, COMITÉ DE DERECHOS HUMANOS DE LAS NACIONES UNIDAS, Concluding observations of the sixth periodic report of the United Kingdom of Great Britain and Northern Ireland, CCPR/C/SR.2542, 21 de julio de 2008, párr. 9).

${ }^{34}$ COMITÉ DE DERECHOS HUMANOS, CCPR/C/GBR/CO/7, cit. nota n 32, párr. 8.
} 
Polít. crim. Vol. 12, No 23 (Julio 2017), Art. 3, pp. 78-102.

[http://www.politicacriminal.cl/Vol_12/n_23/Vol12N23A3.pdf]

de las Naciones Unidas del 15 de diciembre de 2004, sobre el estado de derecho y la justicia de transición en las sociedades que sufren o han sufrido conflictos ${ }^{35}$.

Según este informe, el componente justicia de todo proceso político de transición que busque dejar atrás situaciones de violaciones de derechos humanos a gran escala comprende:

"Toda la variedad de procesos y mecanismos asociados con los intentos de una sociedad por resolver los problemas derivados de un pasado de abusos a gran escala, a fin de que los responsables rindan cuentas de sus actos, servir a la justicia y lograr la reconciliación. Tales mecanismos pueden ser judiciales o extrajudiciales y tener distintos niveles de participación internacional (o carecer por completo de ella) así como abarcar el enjuiciamiento de personas, el resarcimiento, la búsqueda de la verdad, la reforma institucional, la investigación de antecedentes, la remoción del cargo o combinaciones de todos ellos". 36

Más allá de esta definición general, no es posible encontrar en el Derecho internacional regulación alguna del contenido específico de los diversos elementos que componen la justicia de transición. De manera que todo lo que tenemos a este respecto es el trabajo de teóricos y profesionales de la justicia de transición, entre los que cabe destacar las directrices de Belfast sobre amnistía y rendición de cuentas de $2013^{37}$. Esta situación es fruto de lo que el relator especial de las Naciones Unidas para la justicia de transición ha calificado como la ausencia de un mínimo consenso sobre la naturaleza, finalidad, alcance y contenido de cada uno de sus elementos ${ }^{38}$.

En efecto, un buen número de autores con una aproximación liberal a la justicia de transición, como es el caso entre otros de Arthur, Dicklitch \& Malik, Little, Lundy \& McGovern, Rubli, y Waldorf, consideran que por abusos de derechos humanos a gran escala se han de entender únicamente las violaciones graves de derechos civiles y políticos (incluyendo también las infracciones graves del DIH) ${ }^{39}$. En consecuencia, para estos

${ }^{35}$ SECRETARIO GENERAL DE LAS NACIONES UNIDAS, Informe: El estado de derecho y la justicia de transición en las sociedades que sufren o han sufrido conflictos, S/2004/969, 15 de diciembre de 2004, parr. 8.

${ }^{36}$ SECRETARIO GENERAL DE LAS NACIONES UNIDAS, Informe: El estado de derecho, cit. nota $\mathrm{n}^{\circ} 35$, parr. 8 .

37 MALLINDER, Louise y HADDEN, Tom, Belfast Guidelines on Amnesty and Accountability, Ulster: Transitional Justice Institute, 2013.

38 DE GREIFF, Pablo, “Theorizing Transitional Justice”, en: WILLIAMS, Melissa; NAGY, Rosemary y ELSTER, Jon (Eds.), Transitional Justice, Nueva York: New York University Press, 2012, p. 32.

39 ARTHUR, Paige, "How Transitions Reshaped Human Rights: A Conceptual History of Transitional Justice", Human Rights Quarterly, vol. 31 (2009), p. 326; DICKLITCH, Susan y MALIK, Aditi, "Justice, Human Rights and Reconciliation in Postconflict Cambodia", Human Rights Review, vol. 11 (2010), pp. 515530; LITTLE, David, "A Different Kind of Justice: Dealing with Human Rights Violations in Transitional Societies", Ethics and International Affairs, vol. 13, $\mathrm{n}^{\circ} 1$ (1999), pp. 65-80; LUNDY, Patricia y McGOVERN, Mark, "The Role of the Community in Participatory Justice", en: McEVOY, Kieran y McGREGOR, Lorna (Eds.), Transitional Justice from Below: Grassroots Activism and the Struggle for Change, Oxford: Hart Publishing, 2008, p. 104; RUBLI, Sandra, Transitional Justice: Justice by Bureaucratic Means?, Bern: Swiss Peace, 2012, p. 3; WALDORF, Lars, "Anticipating the Past: Transitional Justice and Socio-Economic Wrongs”, Social \& Legal Studies, vol. 21 (2012), pp. 1-16. 
OLASOLO, Héctor. "La inseguridad jurídica de los acuerdos de paz a la luz del régimen jurídico internacional de los crímenes de ius cogens y la justicia de transición”.

autores, los procesos políticos de transición deben poner el acento en: (i) abandonar aquellas formas de organización socio-política que impide la satisfacción de los derechos civiles y políticos debido a sus características estructurales; (ii) promover el estado de derecho; (iii) establecer mecanismos formales de representación democrática; y (iv) fomentar un adecuado equilibrio entre medidas de justicia retributiva y restaurativa. Esto significa que la adopción de medidas de justicia distributiva específicamente dirigidas a promover transformaciones socio-económicas de media y larga duración excedería el ámbito de la justicia de transición, que fue originalmente concebido como un conjunto de medidas de reconstrucción institucional de relativa corta duración en el marco de las revoluciones democráticas que tuvieron lugar en América Latina y Europa en las décadas de 1970 y $1980^{40}$.

Un segundo grupo de autores, incluyendo a Addisson, Arbour, De Greiff, Duthie, Fuller, Miller, Muvingi, Oosterveld, y Roth no comparten esta posición porque, en su opinión, en aquellas situaciones en las que se han cometido violaciones a gran escala de derechos civiles y políticos, se dan simultáneamente violaciones de otro tipo de derechos, incluyendo las generadas por la violencia socio-económica, étnico-cultural y de género ${ }^{41}$. En consecuencia, para estos autores, es necesario adoptar medidas de justicia distributiva que vayan específicamente dirigidas a abordar las mismas.

Sin embargo, los desacuerdos entre este segundo grupo de autores surgen a la hora de determinar el alcance y contenido de las medidas específicas de justicia distributiva que han de adoptarse con tal fin. Así, Addisson, De Greiff, y Duttie, consideran que, en los procesos políticos de transición, la justicia distributiva tiene que articularse de manera sensible a los procesos de desarrollo, evitando asumir objetivos que la superan porque de lo contrario su más que probable incumplimiento no haría sino generar una perdida general de confianza en la misma ${ }^{42}$.

Por su parte, Arbour, Miller y Muvingi sostienen la insuficiencia de esta "articulación sensible" entre justicia distributiva y desarrollo, por lo que la justicia de transición debe

\footnotetext{
${ }^{40}$ Al respecto ver: ARTHUR, "How Transitions Reshaped”, cit. nota n 39, p. 326; LUNDY/ McGOVERN, "The Role of the Community", cit. nota n' 39, p. 104.

${ }^{41}$ ADDISSON, Tony, "The Political Economy of the Transition from Authoritarianism”, en: DE GREIFF, Pablo y DUTHIE, Roger (Eds.), Transitional Justice and Development, Nueva York: Social Science Research Network, 2009, p. 114; ARBOUR, Louise, "Economic and Social Justice for Societies in Transition", $N Y U$ Journal of Law and Politics, vol 40 (2007), p. 3; DE GREIFF, "Theorizing”, cit. nota n 38; DUTHIE, Roger, "Towards a Development Sensitive Approach to Transitional Justice", International Journal of Transitional Justice, vol. 2 (2008), pp. 292-309; FULLER, Lisa, "Burdened Societies and transitional Justice", Ethical Theory and Moral Practice, vol. 25 (2012), pp. 369-386; MILLER, Zinaida, "Effects of Invisibility: In Search of the 'Economic' in Transitional Justice", International Journal of Transitional Justice, vol. 2 (2008)., pp. 266-291; MUVINGI, Ismael, "Sitting on Powder Kegs: Socio-Economic Rights in Transitional Societies", International Journal of Transitional Justice, Vol. 3, N² (2009), p. 168-169; OOSTERVELD, Valerie, “The Special Court for Sierra Leone's Consideration of Gender-Based Violence: Contributing to Transitional Justice?", Human Rights Review, vol. 12 (2008), pp. 73-98; ROTH, Kenneth, "Defending Economic. Social and Cultural Rights: Practical Issues Faced by an International Human Rights Organization", Human Rights Quarterly, vol. 26 (2004), pp. 63-65.

${ }^{42}$ ADDISSON, "The Political Economy", cit nota n 40. p. 114; DE GREIFF, "Theorizing", cit. nota $n^{\circ} 38$; DUTHIE, “Towards a Development", cit. nota n 41, pp. 292-309.
} 
Polít. crim. Vol. 12, № 23 (Julio 2017), Art. 3, pp. 78-102.

[http://www.politicacriminal.cl/Vol_12/n_23/Vol12N23A3.pdf]

tener la ambición de transformar las sociedades oprimidas en sociedades libres mediante la exposición y confrontación de las causas de las violaciones sistemáticas de los derechos económicos, sociales y culturales, y de las prácticas de discriminación desarrolladas antes y durante los conflictos ${ }^{43}$.

Es desde esta última perspectiva que un tercer grupo de autores que representan a las teorías críticas, como McAuliffe, Nagy, Thommason y Young, nos advierten sobre los riesgos de las "transiciones superficiales" 44 . En efecto, McAuliffe y Nagy parten del concepto de "violencia estructural" fruto de la existencia de violencias múltiples en las situaciones de "abusos a gran escala", que no son sino el síntoma a través del cual se manifiesta la violencia estructural, que tiene su origen en aquellas formas de organización de la sociedad cuya columna vertebral es el establecimiento de relaciones de poder manifiestamente desiguales entre sus miembros, lo que genera notables disparidades en cuanto a sus oportunidades de vida ${ }^{45}$. Por su parte, Young prefiere utilizar el concepto de "injusticia estructural", que tiene lugar cuando "los procesos sociales colocan a amplios grupos de personas bajo la amenaza sistemática de dominación o de privación de los medios necesarios para poder desarrollar y ejercitar sus capacidades, al tiempo que o bien colocan a otros en situación de dominación o les atribuyen una amplia variedad de medios para desarrollar y ejercitar sus capacidades" ${ }^{\prime 46}$.

Según este tercer grupo de autores, la violencia o injusticia estructural provoca con frecuencia reacciones violentas en quienes la padecen, y contra-reacciones generalmente más violentas por parte de quienes la administran, lo que, en ocasiones, da lugar a la aparición de conflictos armados, en los que la violencia provocada por las acciones armadas se desarrolla simultáneamente a la violencia estructural ${ }^{47}$. Al menos la mitad de los informes presentados en 2015 por la Comisión para la Historia del Conflicto y de las Víctimas en Colombia, recurren a este concepto de violencia estructural para explicar los orígenes y las causas del conflicto armado en Colombia ${ }^{48}$.

\footnotetext{
${ }^{43}$ ARBOUR, "Economic and Social Justice", cit. nota n' 41, p. 3; MILLER, "Effects of Invisibility", cit. nota $\mathrm{n}^{\circ}$ 41, pp. 266-291; MUVINGI, "Sitting on Powder Kegs", cit. nota ${ }^{\circ} 41$, pp. 168-169.

44 McAULIFFE, Padraif, "Structural Causes of Conflict and the Superficiality of Transition", en: CORRADETTI, Claudio; EISIKOVITS, Nir; ROTONDI, Jack (Eds.), Theorizing Transitional Justice, Surrey: Ashgate, 2014, pp. 93-94; NAGY, “Transitional Justice”, cit. nota n 6, pp. 216-217; THOMASSON, Krista, "Transitional Justice as Structural Justice", en: CORRADETTI, Claudio; EISIKOVITS, Nir; ROTONDI, Jack (Eds.), Theorizing Transitional Justice, Surrey: Ashgate, 2014, p. 71; YOUNG, Iris, Responsibility for Justice, Oxford: Oxford University Press, 2011, p. 52.

${ }^{45}$ McAULIFFE, "Structural Causes", cit. nota n 44, pp. 93-94; NAGY, "Transitional Justice”, cit. nota n 6 , pp. 216-217. Esta posición había sido ya anticipada por GALTUNG, Johan, "Violence, peace, and peace research", Journal of Peace Research, vol. 6, n 3 (1969), pp. 167-191.

${ }^{46}$ YOUNG, Responsibility for Justice, cit. nota $n^{\circ} 44$, p. 52. Traducción del autor.

47 THOMASSON, "Transitional Justice", cit. nota n 44, p. 71; McAULIFFE, "Structural Causes", cit. nota $\mathrm{n}^{\circ} 44$, pp. 93-94.

48 COMISIÓN HISTÓRICA DEL CONFLICTO Y SUS VÍCTIMAS, Contribución al entendimiento del conflicto armado en Colombia, febrero de 2015. En esta Comisión participaron catorce académicos nombrados de común acuerdo por el gobierno de Colombia y las FARC-EP. El informe final de la misma contiene 12 informes, cada uno elaborado por uno de los miembros de la Comisión, y dos relatorías escritas respectivamente por Eduardo Pizarro Leongómez ("Una lectura múltiple y pluralista de la historia”), y Víctor Manuel Moncayo Cruz ("Hacia la verdad del conflicto: insurgencia guerrillera y orden social vigente"). De los 12 informes presentados, los conceptos de violencia o injusticia estructural se recogen en los siguientes 6
} 
OLASOLO, Héctor. "La inseguridad jurídica de los acuerdos de paz a la luz del régimen jurídico internacional de los crímenes de ius cogens y la justicia de transición”.

En cuanto a las razones que explicarían esta ausencia de consenso entre los teóricos de la justicia de transición sobre la naturaleza, finalidad, alcance y contenido de sus elementos, Benavides considera que la razón última se encuentra en la pretensión de extender su aplicación a dos tipos muy diferentes de procesos políticos de transición: (i) los que llevan de regímenes autoritarios a sistemas democráticos; y (ii) los que recorren el camino desde conflictos armados hasta situaciones de paz $^{49}$. Por su parte, Galaín y Reátegui ven el origen de este desencuentro en el hecho de que la justicia de transición contiene elementos políticos, sociales, económicos y culturales que van mucho más allá del ámbito estrictamente jurídico 50 .

Pero más allá de las diversas razones que explicarían esta falta de consenso, lo cierto es que el mismo tiene como consecuencia la ausencia de toda regulación en el Derecho internacional de los diversos elementos que conforman la justicia de transición, limitándose todo su reconocimiento normativo a una definición muy general recogida en una norma de soft law. Es esta situación, unida al consolidado marco normativo de los crímenes de ius cogens, que justifican, desde una perspectiva estrictamente normativa, el contenido de los informes que hemos visto del Comité de Derechos Humanos en relación a España y a Gran Bretaña e Irlanda del Norte.

\section{La inidoneidad de las vías de hecho para modificar el marco normativo vigente de los crímenes de ius cogens.}

Es en este contexto que teóricos y profesionales de la justicia de transición, en lugar de ponerse manos a la obra para aproximar sus posiciones sobre la naturaleza, finalidad, alcance y contenido de los elementos de la justicia de transición, han optado por la estrategia opuesta: hacer en gran medida oídos sordos a las exigencias derivadas del régimen jurídico internacional vigente de los crímenes de ius cogens, con la esperanza de forzar a través de una política de hechos consumados un cambio en su contenido.

informes de DE ZUBIRÍA, S., Dimensiones Políticas y Culturales en el Conflicto Colombiano; ESTRADA ALVAREZ, J., Acumulación Capitalista, Dominación de Clase y Rebelión Armada; FAJARDO, D., Estudio sobre los orígenes del conflicto social armado, razones de su persistencia y sus efectos más profundos en la sociedad colombiana; GIRALDO, J., Aportes Sobre el Origen del Conflicto Armado en Colombia, su Persistencia y sus Impactos: PECAULT, D., Un Conflicto Armado al Servicio del Status Quo Social y Político; VEGA, R. Injerencia de los Estados Unidos, Contrainsurgencia y Terrorismo de Estado; y la relatoría de MONCAYO CRUZ, V., Hacia la verdad del conflicto: insurgencia guerrillera y orden social vigente. Los conceptos de violencia o injusticia estructural no se recogen, sin embargo, en los otros 6 informes, ni en la relatoría de PINZÓN LEONGÓMEZ, E., Una lectura múltiple y pluralista de la historia. Vid. en este sentido los informes de DUNCAN, G., Exclusión, insurrección y crimen; GIRALDO, Jorge, Política y guerra sin compasión; GUTIÉRREZ, F., ¿Una historia simple?, MOLANO, A., Fragmentos de la historia del conflicto armado (1920-2010); TORRIJOS, V., Cartografía del conflicto: pautas interpretativas sobre la evolución del conflicto irregular colombiano; y WILLS, M.E., Los tres nudos de la guerra colombiana. Así mismo tampoco hace referencia expresa o implícita a estos conceptos la relatoría de PINZÓN LEONGÓMEZ, E., Una lectura múltiple y pluralista de la historia.

${ }^{49}$ BENAVIDES, Farid, Justicia en Épocas de Transición, Bogotá: Ibañez, 2013, p. 9.

${ }^{50}$ GALAIN, Pablo, "A Modo de Conclusión”, en: GALAIN, Pablo (Ed.), ¿Justicia de Transición? Mecanismos Políticos y Jurídicos para la Elaboración del Pasado, Valencia: Tirant lo Blanch, 2016, p. 393; REATEGUI, Félix, "Introducción", en: REATEGUI, Félix (Coord.), Justicia Transicional. Manual para América Latina, New York \& Brasilia: International Center for Transitional Justice \& Amnesty Commission, 2011, p. 36. 
Polít. crim. Vol. 12, No 23 (Julio 2017), Art. 3, pp. 78-102.

[http://www.politicacriminal.cl/Vol_12/n_23/Vol12N23A3.pdf]

Esta dinámica se ha observado con particular intensidad en los últimos años en el diseño del componente de justicia penal de los modelos de transición aplicables en Colombia, como lo muestran las constantes preocupaciones expresadas por la Fiscalía de la Corte Penal Internacional en relación con el tratamiento dado por el Marco Jurídico para la Paz aprobado en 2012 a los máximos responsables de genocidio, crímenes de lesa humanidad y crímenes de guerra - incluyendo las facultades conferidas al Congreso de la República para legislar sobre: (i) el establecimiento de una prohibición al Fiscal General de la Nación para ejercitar la acción penal por delitos de ius cogens frente a la gran mayoría de sus responsables (sólo se excluye esta posibilidad frente a quienes califiquen como "máximos responsables"); (ii) el establecimiento de penas alternativas de reclusión por este tipo de delitos sin una duración mínima obligatoria de las mismas; (iii) el cumplimiento de estas penas alternativas conforme a regímenes especiales, como la detención domiciliaria; y (iv) la suspensión, bajo ciertas condiciones, de su ejecución (medida finalmente declarada inexequible por la Corte Constitucional de Colombia) ${ }^{51}$. Las recomendaciones emitidas por la Comisión Inter-Americana de Derechos Humanos en 2014 para que Colombia enmiende el Marco Jurídico para la Paz y sus leyes estatutarias, de manera que lo haga compatible con sus obligaciones de investigación, enjuiciamiento, sanción penal y reparación integral recogidas en los artículos 1(1), 8 y 25 de la Convención Americana de Derechos Humanos, constituyen otro buen ejemplo de esta situación ${ }^{52}$.

Varios aspectos del Sistema Integral de Verdad, Justicia, Reparación y No Repetición (SIVJRNR), recogido en el acuerdo de paz firmado el 26 de septiembre de 2016 entre el Gobierno de Colombia y las FARC-EP, generan este mismo tipo de inquietudes. Este es el caso de (i) la expresa extensión a la Jurisdicción Especial para la Paz ("JEP”) del fuero del que disfrutan, conforme al artículo 174 de la Constitución de Colombia, quienes han ejercido la Presidencia de la República, lo que, dada la práctica de la Comisión de Acusaciones del Congreso, supone de hecho una garantía de que no responderán por crímenes de ius cogens ante la $\mathrm{JEP}^{53}$; (ii) la limitación a un máximo de 20 años de reclusión para los responsables de estos crímenes (incluidos los máximos responsables) que no cumplan con ninguno de los presupuestos de la justicia transicional (y por lo tanto no puedan ser acreedores de una pena alternativa), al no reconocer su responsabilidad, no colaborar con la justicia, no pedir perdón a las víctimas, no entregar bienes para la

\footnotetext{
51 Ver en FISCALÍA DE LA CORTE PENAL INTERNACIONAL, Situación en Colombia, Reporte Intermedio, 12 de noviembre de 2012. Las preocupaciones mostradas en este informe, han sido reiteradas por la Fiscalía en posteriores informes sobre el examen preliminar en Colombia. Véase FISCALÍA DE LA CORTE PENAL INTERNACIONAL, Report on Preliminary Examination Activities 2013, 25 de noviembre de 2013; FISCALÍA DE LA CORTE PENAL INTERNACIONAL, Report on Preliminary Examination Activities 2014, 2 de diciembre de 2014; FISCALÍA DE LA CORTE PENAL INTERNACIONAL, Report on Preliminary Examination Activities 2015, 12 de noviembre de 2015; y FISCALÍA DE LA CORTE PENAL INTERNACIONAL, Report on Preliminary Examination Activities 2016, 14 de noviembre de 2016. Véase también, OLASOLO, Héctor, "Los exámenes preliminares de la Corte Penal Internacional en América Latina: el caso colombiano y su impacto sobre futuras negociaciones de paz", Anuario de Derechos Humanos, Vol. 10 (2014), pp. 35-56.

52 COMISIÓN INTERAMERICANA DE DERECHOS HUMANOS, Country Reports: Colombia, Truth, Justice and Reparation, 31 de diciembre de 2013, pp. 185-194. Disponible en: http://www.oas.org/en/iachr/reports/pdfs/Colombia-Truth-Justice-Reparation.pdf [visitado el 15/09/2016].

${ }^{53}$ GOBIERNO DE COLOMBIA Y FARC-EP, Acuerdo de 26 de septiembre de 2016, cit. nota n ${ }^{\circ}$ 1, p. 134.
} 
OLASOLO, Héctor. "La inseguridad jurídica de los acuerdos de paz a la luz del régimen jurídico internacional de los crímenes de ius cogens y la justicia de transición”.

reparación y ser declarados culpables solamente tras un proceso penal contradictorio ${ }^{54}$; (iii) el establecimiento para todo tipo de responsables (autores materiales, mandos medios y máximos responsables) que sí cumplan con dichos presupuestos, y admitan su responsabilidad antes del inicio del juicio oral, de penas alternativas (restricción de derechos tales como la realización de trabajos comunitarios, o prohibición de salir de ciertas regiones geográficas durante 5 a 8 años) ${ }^{55}$, que, contrariamente a la práctica constante y uniforme de los Tribunales internacionales e internacionalizados de carácter penal establecidos desde la II Guerra Mundial ${ }^{56}$ y al fin central del régimen jurídico de los crímenes de ius cogens de enviar el mensaje de que no se tolerará la impunidad de los máximos responsables de dichos delitos (prevención general positiva) ${ }^{57}$, excluyen la pena de reclusión (algo que no sucede con la Ley de Justicia y Paz de 2005); y (iv) la distinción entre delitos de ius cogens "muy graves" y delitos de ius cogens que no merecen dicha calificación, para discriminar entre diferentes tipos de penas alternativas ${ }^{58}$. Así mismo, llama la atención, que la JEP sólo conozca de los crímenes de guerra calificados como "graves", lo que supone afirmar, en sentido contrario, la existencia de crímenes de guerra que, a pesar de constituir crímenes de ius cogens, no son graves, y que, a diferencia de lo dispuesto en la Ley de Justicia y Paz, las víctimas no tengan reconocida una posición procesal propia en las actuaciones ante las Salas y Tribunal de la JEP ${ }^{59}$.

\footnotetext{
${ }^{54}$ GOBIERNO DE COLOMBIA Y FARC-EP, Acuerdo de 26 de septiembre de 2016, cit. nota ${ }^{\circ} 1$, pp. 147148.

${ }^{55}$ GOBIERNO DE COLOMBIA Y FARC-EP, Acuerdo de 26 de septiembre de 2016, cit. nota ${ }^{\circ} 1$, pp. 147148.

${ }^{56}$ La pena de reclusión ha sido la pena central de los Tribunales de Nuremberg y Tokyo tras la II Guerra Mundial, así como de aquellos creados a partir de 1990, como son el Tribunal Internacional para la Ex Yugoslavia, el Tribunal Internacional para Ruanda, la Corte Especial para Sierra Leona, las Salas Especiales de los Tribunales de Camboya o el Tribunal Especial para el Líbano. Igualmente, el artículo 77 del Estatuto de la Corte Penal Internacional establece pena principal la reclusión en centro penitenciario hasta un máximo de treinta años, con la posibilidad de su extensión a la cadena perpetua revisable en caso de concurran dos circunstancias agravantes. Según esta disposición, las penas de multa y decomiso pueden imponerse de manera complementaria a la pena de reclusión, pero nunca de manera alternativa a la misma. D’ASCOLI, S. Sentencing in International Criminal Law: The approach of the two UN ad hoc Tribunals and future perspectives for the International Criminal Court. Oxford: Hart Publishing Ltd., 2011.

${ }^{57}$ Los siguientes autores consideran que el fin central del Derecho internacional penal es transmitir el mensaje de que no se tolerará la impunidad de los máximos responsables de dichos delitos (prevención general positiva): AMBOS, Kai, "Crímenes de Lesa Humanidad y la Corte Penal Internacional", Cuadernos de Derecho Penal, $\mathrm{N}^{\circ} 9$ (2013), p. 71; CRYER, Robert, Prosecuting International Crimes: Selectivity and the International Criminal Law Regime, Cambridge: Cambridge University Press, 2005, p. 191; DAMARSKA, Mirjan, "What is the Point of International Criminal Law", Chicago Kent Law Review, vol. 83 (2008), pp. 350-356; DRUMBL, Mark, "Collective Violence and Individual Punishment: The Criminality of Mass Atrocity", Northwestern University Law Review, vol. 99 (2005), p. 173; DUFF, Anthony, "Can We Punish the Perpetrators of Atrocities?", en: BRUDHOLM, Thomas y CUSHMAN, Thomas (Eds.), The Religious in Responses to Mass Atrocity, Cambridge: Cambridge University Press, 2008, pp. 85-100; STAHN, Carsten, "Between Faith and Facts: By What Standards Should We Assess International Criminal Justice?", Leiden Journal of International Law, vol. 25 (2012), p. 251; EIROA, Pablo, Políticas del castigo y derecho internacional. Para una concepción minimalista de la justicia penal, Buenos Aires; Ad Hoc. 2009. Para un mayor desarrollo sobre la relevancia de la prevención general positiva entre los fines del Derecho internacional penal, vid. OLASOLO, Hector, "Fines del Derecho Internacional Penal", International Law, Universidad Javeriana. Vol. 27 (Diciembre 2016) (en prensa).

${ }^{58}$ GOBIERNO DE COLOMBIA Y FARC-EP, Acuerdo de 26 de septiembre de 2016, p. 134.

${ }^{59}$ GOBIERNO DE COLOMBIA Y FARC-EP, Acuerdo de 26 de septiembre de 2016, p. 136.
} 
Polít. crim. Vol. 12, № 23 (Julio 2017), Art. 3, pp. 78-102.

[http://www.politicacriminal.cl/Vol_12/n_23/Vol12N23A3.pdf]

El nuevo acuerdo alcanzado el 12 de noviembre de 2016 entre el gobierno de Colombia y las FARC, y rechazado al día siguiente por insuficiente por los principales defensores del "no" en el referéndum del 2 de octubre, ratifica todos estos elementos, en cuanto que acoge el modelo de penas (y también el de participación de víctimas) previsto en el acuerdo de 26 de septiembre.

La única salvedad es que se limita a "Zonas Veredales Transitorias de Normalización" la extensión de las regiones geográficas a las que se verán confinados los condenados por aquellos crímenes de ius cogens que sean considerados como "muy graves", que se recoge una reglamentación más detallada del régimen en que se cumplirá este tipo de pena alternativa, y que se prevé de manera expresa (en el acuerdo de 26 de septiembre se encontraba implícito) la entrega de bienes por parte de las FARC a los efectos de la reparación, sancionándose con la pérdida de la penal alternativa a quien pretenda ocultarlos ${ }^{60}$.

Ahora bien, los avances que suponen estos nuevos aspectos del régimen de penas, se ve ciertamente empañado por la introducción de varias de las propuestas más preocupantes presentadas por algunos de los defensores del "no" en el referéndum del 2 de octubre, como es el caso de extender el ámbito de la JEP a los casos de falsos positivos (cuya investigación, enjuiciamiento y sanción, se ha convertido desde el informe del 12 de noviembre de 2012 en la principal exigencia de la Fiscalía de la Corte Penal Internacional en relación con los crímenes de lesa humanidad y de guerra cometidos por agentes del Estado colombiano), o la expresa imposición de plazos máximos para que la Fiscalía General de la Nación envíe sus informes de investigación a las salas de las JEP (2 años ,prorrogables a un máximo de 3), y para que estas últimas desempeñen sus funciones ${ }^{61}$. De esta manera, en lugar de solventar la mayor parte de los problemas identificados en el acuerdo del 26 de septiembre, el nuevo acuerdo de 12 de noviembre parece estar abocado a generar dificultades adicionales.

En cualquier caso, y con independencia de que el texto del nuevo acuerdo del 12 de noviembre sea objeto o no de futuras modificaciones, algo que en la actual situación de incertidumbre política que vive el país apenas una semana después de su firma, no se puede predecir, lo cierto es que no creemos que una política de hechos consumados sea la manera más idónea para "forzar" un cambio en el régimen jurídico internacional vigente para el genocidio, los crímenes de lesa humanidad y los crímenes de guerra. Además de no contar con la necesaria legitimidad normativa, está abocada a colocar a los actores involucrados en una incertidumbre jurídica permanente, porque nadie puede garantizarles que los propios tribunales nacionales colombianos, los órganos jurisdiccionales de terceros países actuando conforme al principio de justicia universal, y los tribunales internacionales penales, vayan a renunciar de manera permanente a aplicar el marco normativo vigente para los crímenes de ius cogens.

\footnotetext{
${ }^{60}$ Vid. también GOBIERNO DE COLOMBIA Y FARC-EP, Acuerdo Final de 12 de noviembre, cit. nota ${ }^{\circ}$ 11 , pp. 165-166, 186.

${ }^{61}$ GOBIERNO DE COLOMBIA Y FARC-EP, Acuerdo Final de 12 de noviembre, cit. nota ${ }^{\circ} 11$, pp. 145, 153 y 165-16., Ver también COMISIÓN INTERAMERICANA DE DERECHOS HUMANOS, Country Reports: Colombia, Truth, Justice and Reparation, cit. nota $\mathrm{n}^{\circ} 52$.
} 
OLASOLO, Héctor. "La inseguridad jurídica de los acuerdos de paz a la luz del régimen jurídico internacional de los crímenes de ius cogens y la justicia de transición”.

Por si esto fuera poco, una política de estas características parece estar condenada al fracaso, debido a la gran capacidad de resistencia mostrada por el régimen jurídico internacional del genocidio, los crímenes de lesa humanidad y los crímenes de guerra, frente a los repetidos intentos de obstaculizar su aplicación. Esta capacidad de resistencia tiene sus raíces en la transformación que es inherente al Derecho internacional penal, puesto que, a diferencia del derecho nacional y transnacional penal ${ }^{62}$, el Derecho internacional penal se dirige, en particular, a todos aquellos dirigentes que tradicionalmente han estado por encima de la ley, y que utilizan los resortes del poder para que se lleven a cabo acríticamente las más horrorosas atrocidades ${ }^{63}$. Es por ello que la Fiscalía de la Corte Penal Internacional centra sus actuaciones en los "máximos responsables" de crímenes de ius cogens $^{64}$, de la misma manera que el Consejo de Seguridad de las Naciones Unidas ha terminado limitando la jurisdicción personal de los Tribunales Internacionales Penales para la ex Yugoslavia y Ruanda a las "personas con la mayor responsabilidad"65.

\section{Conclusión.}

Si bien el régimen jurídico internacional vigente de los crímenes de ius cogens es normativamente prevalente sobre el prácticamente inexistente anclaje jurídico de los elementos característicos de la justicia de transición, sería un error rechazar de plano todas

${ }^{62}$ Los últimos desarrollos de la regulación jurídica de los delitos transnacionales más relevantes, y en particular del terrorismo, han estado en gran medida basados en el llamado "Derecho penal del enemigo". Véase a este respecto JAKOBS, Günther y CANCIO MELIÁ, Manuel, Derecho penal del enemigo, Madrid: Civitas, 2006 y VERVAELE, John, "La legislación antiterrorista en Estados Unidos: inter arma silent leges", Revista de Derecho y Proceso Penal, vol. 14 (2005), pp. 116 y ss. Para una aproximación crítica a estos desarrollos, véase BUSTOS RAMÍREZ, Juan, "In-seguridad y la lucha contra el terrorismo", en: LOSANO, Mario y MUÑOZ CONDE, Francisco (Coords.), El Derecho ante la globalización y el terrorismo, "cedant arma togae", Valencia: Tirant lo Blanch, 2004, p. 407; ZAFFARONI, Eugenio; ALAGIA, Alejandro y SLOKAR, Alejandro, Derecho penal. Parte General, Buenos Aires: Ediar, 2000, p. 17; MUÑOZ CONDE, Francisco, "El nuevo Derecho penal autoritario", en: CORTES BECHIARELLI, Emilio; OCTAVIO DE TOLEDO, Emilio y GURDIEL SIERRA, Manuel (Coords.) Estudios penales en Recuerdo del profesor Ruiz Antón, Valencia: Tirant lo Blanch, 2003; OLASOLO, Héctor y PÉREZ CEPEDA, Ana Isabel, Terrorismo y Conflicto Armado, capítulo II. Valencia: Tirant lo Blanch, 2008.

${ }^{63}$ ARENDT, Hannah, Eichmann in Jerusalem: A Report on the Banality of Evil, Londres: Penguin Group, 1963.

${ }^{64}$ Ver COMISIÓN INTERAMERICANA DE DERECHOS HUMANOS, Country Reports: Colombia, Truth, Justice and Reparation, cit. nota $\mathrm{n}^{\circ} 52$.

${ }^{65}$ CONSEJO DE SEGURIDAD DE LAS NACIONES UNIDAS, Resolución 1534 sobre el Tribunal Internacional Penal para la ex Yugoslavia y el Tribunal Internacional Penal para Ruanda, UN. Doc. S/RES/1534, 26 de marzo de 2004, párr. 5 y 6. En esta resolución, el Consejo de Seguridad, entre otras cosas: (i) "insta a cada uno de los Tribunales a que, al examinar y confirmar las acusaciones nuevas, se aseguren de que concentran la labor en el procesamiento de los más altos dirigentes de quienes se sospeche que les cabe la mayor responsabilidad respecto de los delitos que sean de competencia del Tribunal de que se trate, según se establece en la resolución 1503 (2003)"; y (ii) "pide a cada uno de los Tribunales que proporcionen al Consejo, a más tardar el 31 de mayo de 2004 y semestralmente después de esa fecha, evaluaciones realizadas por su Presidente y su Fiscal en que se expongan en detalle los progresos logrados en la aplicación de su estrategia de conclusión, se expliquen las medidas adoptadas y pendientes de aplicación, incluida la remisión de las causas relativas a inculpados de rango medio o inferior a jurisdicciones nacionales competentes, y expresa la intención del Consejo de reunirse con el Presidente y el Fiscal de cada Tribunal para examinar esas evaluaciones". Véase también a este respecto, CONSEJO DE SEGURIDAD DE LAS NACIONES UNIDAS, Resolución 1503 sobre el Tribunal Internacional Penal para la ex Yugoslavia (TIPY) y el Tribunal Internacional Penal para Ruanda, UN. Doc. S/RES/1503, 28 de agosto de 2003. 
Polít. crim. Vol. 12, No 23 (Julio 2017), Art. 3, pp. 78-102.

[http://www.politicacriminal.cl/Vol_12/n_23/Vol12N23A3.pdf]

las preocupaciones expresadas por los teóricos de la justicia de transición, a la luz de la amplia experiencia acumulada en los últimos veinticinco años. Del mismo modo, recurrir a las vías de hecho, como se ha hecho en Colombia, España o Irlanda del Norte para a través de una política de hechos consumados tratar de "forzar" un cambio en dicho régimen jurídico, es sin duda la estrategia equivocada, dada la inseguridad jurídica que genera, y el alto grado de resistencia que el marco normativo del genocidio, los crímenes de lesa humanidad y los crímenes de guerra ha mostrado ante los numerosos obstáculos a los que se ha enfrentado en su aplicación.

Lo que se requiere en este momento es poner fin a este "diálogo de sordos" que desde hace más de dos décadas ha caracterizado a quienes están llamados a entenderse al tener ámbitos de actuación superpuestos. Esta reactivación de la comunicación entre los teóricos de la justicia de transición y los defensores del marco normativo de los crímenes de ius cogens, debería, de lege ferenda, propiciar una revisión de este último, con el fin de tratar de armonizar el contenido jurídico de las obligaciones de los Estados de investigar, enjuiciar y sancionar a los responsables de crímenes de ius cogens, así como de reparar íntegramente a las víctimas (y los correlativos derechos de las víctimas a la verdad, la justicia y la reparación), con las exigencias derivadas de la necesidad de articular procesos políticos de transición que permitan superar las situaciones en que se cometen los mismos.

Para ello, constituye una condición sine qua non que los teóricos de la justicia de transición hagan un esfuerzo para alcanzar un mínimo grado de consenso sobre la naturaleza, finalidad, alcance y contenido de los distintos elementos que conforman la misma. Se trata este de un paso previo a cualquier reconocimiento y regulación que de dichos elementos se pretenda realizar en el Derecho internacional. Sólo entonces será posible realizar una revisión comprehensiva del actual marco normativo de los crímenes de ius cogens con el fin de integrar, en la medida de lo posible, las exigencias irrenunciables del mismo, como la investigación, enjuiciamiento y sanción penal de los máximos responsables, con las demandas centrales planteadas desde la justicia de transición. 
OLASOLO, Héctor. "La inseguridad jurídica de los acuerdos de paz a la luz del régimen jurídico internacional de los crímenes de ius cogens y la justicia de transición”.

\section{BIBLIOGRAFÍA CITADA}

ACOSTA, Diego; BUCHAN, Russell y UREÑA, René, "Beyond Justice, Beyond Peace? Colombia, the Interests of Justice, and the Limits of International Criminal Law", Criminal Law Forum, Volume 26, n 2, (2015), pp. 291-318.

ADDISSON, Tony, "The Political Economy of the Transition from Authoritarianism", en: DE GREIFF, Pablo y DUTHIE, Roger (Eds.), Transitional Justice and Development, Nueva York: Social Science Research Network, 2009.

AMBOS, Kai, "Crímenes de Lesa Humanidad y la Corte Penal Internacional", Cuadernos de Derecho Penal N 9 (2013).

ARBOUR, Louise, "Economic and Social Justice for Societies in Transition", NYU Journal of Law and Politics, vol. 40 (2007).

ARENDT, Hannah, Eichmann in Jerusalem: A Report on the Banality of Evil, Londres: Penguin Group, 1963.

ARTHUR, Paige, "How Transitions Reshaped Human Rights: A Conceptual History of Transitional Justice", Human Rights Quarterly, vol. 31 (2009).

BENAVIDES, Farid, Justicia en Épocas de Transición, Bogotá: Ibañez, 2013.

BUSTOS RAMÍREZ, Juan, "In-seguridad y la lucha contra el terrorismo", en: LOSANO, Mario y MUÑOZ CONDE, Francisco (Coords.), El Derecho ante la globalización y el terrorismo, “cedant arma togae”, Valencia: Tirant lo Blanch, 2004.

CLAMP, Kerry y DOAK, Jonathan, "More than Words: Restorative Justice Concepts in Transitional Justice Settings", International Criminal Law Review vol. 12, $\mathrm{n}^{\circ} 3$ (2012).

COMISIÓN HISTÓRICA DEL CONFLICTO Y SUS VÍCTIMAS, Contribución al entendimiento del conflicto armado en Colombia, febrero de 2015.

COMISIÓN INTERAMERICANA DE DERECHOS HUMANOS, Country Reports: Colombia, Truth, Justice and Reparation, 31 de diciembre de 2013. Disponible en: http://www.oas.org/en/iachr/reports/pdfs/Colombia-Truth-Justice-Reparation.pdf [visitado el 15/09/2016].

COMITÉ DE DERECHOS HUMANOS DE LAS NACIONES UNIDAS, Concluding observations on the seventh periodic report of the United Kingdom of Great Britain and Northern Ireland, CCPR/C/GBR/CO/7, 17 de agosto de 2015.

Concluding observations of the sixth periodic report of the United Kingdom of Great Britain and Northern Ireland, CCPR/C/SR.2542, 21 de julio de 2008.

Concluding observations on the sixth periodic report of Spain, CCPR/C/ESP/CO/6, 14 de agosto de 2015.

General Comment 31, Nature of General Obligation on States Parties to the Covenant, Doc. CCPR/C/21/Rev.1/Add.13, 29 de marzo de 2004.

CONSEJO DE SEGURIDAD DE LAS NACIONES UNIDAS, Resolución 1503 sobre el Tribunal Internacional Penal para la ex Yugoslavia (TIPY) y el Tribunal Internacional Penal para Ruanda, UN. Doc. S/RES/1503, 28 de agosto de 2003.

, Resolución 1534 sobre el Tribunal Internacional Penal para la ex Yugoslavia y el Tribunal Internacional Penal para Ruanda, UN. Doc. S/RES/1534, 26 de marzo de 2004. Disponible en: http://www.un.org/en/ga/search/view_doc.asp?symbol=S/RES/1534(2004) visitado el 15/09/2016]. 
Polít. crim. Vol. 12, № 23 (Julio 2017), Art. 3, pp. 78-102.

[http://www.politicacriminal.cl/Vol_12/n_23/Vol12N23A3.pdf]

CORRADETTI, Claudio; EISIKOVITS, Nir y ROTONDI, Jack, "Introduction”, en: CORRADETTI, Claudio; EISIKOVITS, Nir y ROTONDI, Jack, (Eds.), Theorizing Transitional Justice, Surrey: Ashgate, 2014.

CORTE PENAL INTERNACIONAL, Preámbulo del Estatuto de Roma, 17 de julio de 1998.

Disponible

en:

http://www.un.org/spanish/law/icc/statute/spanish/rome_statute(s).pdf [visitado el 15/09/2016].

CRYER, Robert, Prosecuting International Crimes: Selectivity and the International Criminal Law Regime, Cambridge: Cambridge University Press, 2005.

DAMARSKA, Mirjan, "What is the Point of International Criminal Law", Chicago Kent Law Review, vol. 83 (2008).

DE GREIFF, Pablo, "Theorizing Transitional Justice”, en: WILLIAMS, Melissa; NAGY, Rosemary y ELSTER, Jon (Eds.), Transitional Justice, Nueva York: New York University Press, 2012.

DICKLITCH, Susan y MALIK, Aditi, "Justice, Human Rights and Reconciliation in Postconflict Cambodia”, Human Rights Review, vol. 11 (2010).

DRUMBL, Mark, "Collective Violence and Individual Punishment: The Criminality of Mass Attrocity", Northwestern University Law Review, vol. 99 (2005).

DUFF, Anthony, "Can We Punish the Perpetrators of Atrocities?", en: BRUDHOLM, Thomas y CUSHMAN, Thomas (Eds.), The Religious in Responses to Mass Atrocity, Cambridge: Cambridge University Press, 2008.

DUTHIE, Roger, "Towards a Development Sensitive Approach to Transitional Justice", International Journal of Transitional Justice, vol. 2 (2008).

EIROA, Pablo, Políticas del castigo y derecho internacional. Para una concepción minimalista de la justicia penal, Buenos Aires: Ad Hoc, 2009.

ELSTER, Jon, Closing the Books: Transitional Justice in Historical Perspective, Cambridge: Cambridge University Press, 2004.

FISCALÍA DE LA CORTE PENAL INTERNACIONAL, Draft Policy Paper on Case Selection and Prioritisation, 29 de febrero de 2016, disponible en: https://www.icccpi.int/iccdocs/otp/29.02.16_Draft_Policy-Paper-on-Case-Selection-and-

Prioritisation_ENG.pdf [visitado el 15/09/2016].

, Policy Paper on Preliminary Examinations, 1 de noviembre de 2013, disponible en: https://www.icc-cpi.int//Pages/item.aspx?name=otp-policy-pe-11_2013 [visitado el 15/09/2016].

, Report on Preliminary Examination Activities 2013, 25 de noviembre de 2013. Disponible en: https://www.icc-cpi.int//Pages/item.aspx?name=report-onpreliminary-examination-activities-2013 [visitado el 15/09/2016].

, Report on Preliminary Examination Activities 2014, 2 de diciembre de 2014. Disponible en: https://www.icc-cpi.int//Pages/item.aspx?name=pre-exam2014 [visitado el 15/09/2016].

, Report on Preliminary Examination Activities 2015, 12 de noviembre de 2015. Disponible en: https://www.icc-cpi.int//Pages/item.aspx?name=otp-rep-peactivities-2015 [visitado el 15/09/2016].

, Report on Preliminary Examination Activities 2016, 14 de noviembre de 2016. Disponible en https://www.icc-cpi.int/iccdocs/otp/161114-otp-rep-PE_ENG.pdf. [visitado el 17/11/2016]. 
OLASOLO, Héctor. "La inseguridad jurídica de los acuerdos de paz a la luz del régimen jurídico internacional de los crímenes de ius cogens y la justicia de transición”.

, Situación en Colombia, Reporte Intermedio, 12 de noviembre de 2012. Disponible en la página oficial de la Fiscalía de la CPI: https://www.icccpi.int/nr/rdonlyres/3d3055bd-16e2-4c83-ba85-

35bcfd2a7922/285202/otp2012035032colresumenejecutivodelreporteintermed.pdf [visitado el 15/09/2016].

FULLER, Lisa, "Burdened Societies and transitional Justice", Ethical. Theory and Moral Practice, vol. 25 (2012).

GALAIN, Pablo, "A Modo de Conclusión", en: GALAIN, Pablo (Ed.), ¿Justicia de Transición? Mecanismos Políticos y Jurídicos para la Elaboración del Pasado, Valencia: Tirant lo Blanch, 2016.

GALTUNG, Johan, "Violence, peace, and peace research", Journal of Peace Research, vol. $6, n^{\circ} 3$ (1969), pp. 167-191.

GIL, Alicia, "El tratamiento jurídico de los crímenes cometidos en el conflicto armado colombiano. La problemática jurídica en el marco de la dicotomía paz-justicia”. En ALDA MEJÍAS, Sonia y FERREIRA DE SOUSA, Susana, Semana Iberoamericana. Madrid: IUGM, 2016.

GOBIERNO DE COLOMBIA \& FARC-EP, Borrador Conjunto: 5. Acuerdo sobre las Victimas del Conflicto: "Sistema Integral de Verdad, Justicia, Reparación y No Repetición”, incluyendo la Jurisdicción Especial para la Paz; y Compromiso sobre Derechos Humanos, 15 de diciembre de 2015. Disponible en http://www.altocomisionadoparalapaz.gov.co/procesos-y-conversaciones/procesode-paz-con-las-farc-ep/documentos-y-comunicados-conjuntos/Documents/acuerdovictimas.pdf [visitado el 15/09/2016].

, Acuerdo Final para la Terminación del Conflicto de una Paz Estable y Duradera, firmado el 26 de septiembre de 2016. Disponible en: https://www.mesadeconversaciones.com.co/sites/default/files/acuerdo-final1473286288.pdf [visitado el 15/09/2016].

, Acuerdo Final para la Terminación del Conflicto de una Paz Estable y Duradera, firmado el 12 de noviembre de 2016. Disponible en: http://www.altocomisionadoparalapaz.gov.co/procesos-yconversaciones/Paginas/Texto-completo-del-Acuerdo-Final-para-la-Terminacion-delconflicto.aspx [visitado el 20/12/2016].

JAKOBS, Günther y CANCIO MELIÁ, Manuel, Derecho penal del enemigo, Madrid: Civitas, 2006.

LITTLE, David, “A Different Kind of Justice: Dealing with Human Rights Violations in Transitional Societies", Ethics and International Affairs, vol. 13, n 1(1999).

LUBAN, David, "A Theory of Crimes against Humanity", Yale International Law Journal, vol. 29 (2004).

LUNDY, Patricia y McGOVERN, Mark, “The Role of the Community in Participatory Justice", en: McEVOY, Kieran y McGREGOR, Lorna (Eds.), Transitional Justice from Below: Grassroots Activism and the Struggle for Change, Oxford: Hart Publishing, 2008.

MALARINO, Ezequiel, "Transición, derecho penal y amnistía. Reflexiones sobre la utilización del derecho penal en procesos de transición", Revista de Derecho penal y Criminología, no 9 (2003), pp. 205-222. 
Polít. crim. Vol. 12, № 23 (Julio 2017), Art. 3, pp. 78-102.

[http://www.politicacriminal.cl/Vol_12/n_23/Vol12N23A3.pdf]

MALLINDER, Louise, Amnesty human rights and political transitions: bridging the peace and justice divide, Oxford: Hart, 2008.

MALLINDER, Louise y HADDEN, Tom, Belfast Guidelines on Amnesty and Accountability, Ulster: Transitional Justice Institute, 2013.

McAULIFFE, Padraif, "Structural Causes of Conflict and the Superficiality of Transition", en: CORRADETTI, Claudio; EISIKOVITS, Nir y ROTONDI, Jack (Eds.), Theorizing Transitional Justice, Surrey: Ashgate, 2014.

MILLER, Zinaida, "Effects of Invisibility: In Search of the "Economic in Transitional Justice”, International Journal of Transitional Justice, vol. 2 (2008).

MUÑOZ CONDE, Francisco, "El nuevo Derecho penal autoritario", en: CORTES BECHIARELLI, Emilio; OCTAVIO DE TOLEDO, Emilio y URDIEL SIERRA, Manuel (Coords.), Estudios penales en Recuerdo del profesor Ruiz Antón, Valencia: Tirant lo Blanch, 2003.

MUVINGI, Ismael, "Sitting on Powder Kegs: Socio-Economic Rights in Transitional Societies", International Journal of Transitional Justice, Vol. 3, n 2 (2009).

NAGY, Rosemary, "Transitional Justice as Global Project: Critical Reflections", en: BUCHANAN, Ruth y ZUMBASEN, Peer (Eds.), Law in Transition. Human Rights, Development and Transitional Justice, Oxford: Hart Publishing, 2014.

OLASOLO, Héctor, "El principio 'no hay paz sin justicia' como principio rector del tratamiento del fenómeno de la lesa humanidad por el Derecho internacional y su impacto en los procesos de paz: particular atención al caso colombiano", en: OLASOLO, Introducción al Derecho internacional penal, Valencia: Tirant lo Blanch. Universidad del Rosario \& IIH, diciembre de 2014.

, "Los exámenes preliminares de la Corte Penal Internacional en América Latina: el caso colombiano y su impacto sobre futuras negociaciones de paz", Anuario de Derechos Humanos, Vol. 10 (2014).

"Fines del Derecho International Penal", International Law, Universidad Javeriana. Vol. 27 (Diciembre 2016) (en prensa).

OLASOLO, Héctor y PÉREZ CEPEDA, Ana Isabel, Terrorismo y Conflicto Armado, Valencia: Tirant lo Blanch, 2008.

OLASOLO, Héctor; MARTÍNEZ, Juan y RODRÍGUEZ, Ana María, "La inmunidad de jurisdicción penal por crímenes internacionales de los Jefes de Estado, los Jefes de Gobierno y los Ministros de Asuntos Exteriores", Revista Chilena de Derecho, vol. 43, n 1 (2016), pp. 251-281.

OLASOLO, Héctor; MATEUS, Andrea y CONTRERAS, Andrés, "La naturaleza imperativa del principio "no hay paz sin justicia" respecto a los máximos responsables del fenómeno de la lesa humanidad y sus consecuencias para el ámbito de actuación de la llamada 'justicia de transición”", Boletín Mexicano de Derecho Comparado, $\mathrm{n}^{\circ} 145$ (2016), pp. 167-168.

OOSTERVELD, Valerie, "The Special Court for Sierra Leone's Consideration of GenderBased Violence: Contributing to Transitional Justice?", Human Rights Review, vol. 12 (2008).

OSIEL, Mark, "Why Prosecute? Critics of Punishment for Mass Atrocity", Human Rights Quarterly, vol. 22 (2000). 
OLASOLO, Héctor. "La inseguridad jurídica de los acuerdos de paz a la luz del régimen jurídico internacional de los crímenes de ius cogens y la justicia de transición”.

REATEGUI, Félix, "Introducción”, en: REATEGUI, Félix (Coords.), Justicia Transicional. Manual para América Latina, New York \& Brasilia: International Center for Transitional Justice \& Amnesty Commission, 2011.

ROTH, Kenneth, "Defending Economic. Social and Cultural Rights: Practical Issues Faced by an International Human Rights Organization", Human Rights Quarterly, vol. 26 (2004).

RUBLI, Sandra, Transitional Justice: Justice by Bureaucratic Means?, Bern: Swiss Peace, 2012.

SECRETARIO GENERAL DE LAS NACIONES UNIDAS, Informe: El estado de derecho y la justicia de transición en las sociedades que sufren o han sufrido conflictos, S/2004/969, 15 de diciembre de 2004.

STAHN, Carsten, "Between Faith and Facts: By What Standards Should We Assess International Criminal Justice?", Leiden Journal of International Law, vol. 25 (2012).

TAMARIT, Josep Maria, "Los límites de la justicia transicional penal: la experiencia del caso español”, Política criminal, vol. 7, n 13 (julio 2012), art. 2, pp. 74-93.

TEITEL, Ruti, Transitional Justice, Oxford: Oxford University Press, 2000.

THOMASSON, Krista, "Transitional Justice as Structural Justice", en: CORRADETTI, Claudio; EISIKOVITS, Nir; ROTONDI, Jack (Eds.), Theorizing Transitional Justice, Surrey: Ashgate, 2014.

VACAS FERNÁNDEZ, Félix, "Los Derechos de las Víctimas y la Negociación: El Caso de Colombia", en: DÍAZ BARRADO, Castor; FERNÁNDEZ LIESA, Carlos y RODRÍGUEZ-VILLASANTE, José Luis (Dirs.), Derecho Internacional Humanitario y Derechos Humanos: Reflexiones Sobre el Caso de Colombia, Madrid: Civitas, 2013.

VERVAELE, John, "La legislación antiterrorista en Estados Unidos: inter arma silent leges", Revista de Derecho y Proceso Penal, vol. 14 (2005).

WALDORF, Lars, "Anticipating the Past: Transitional Justice and Socio-Economic Wrongs", Social \& Legal Studies, vol. 21 (2012).

YOUNG, Iris, Responsibility for Justice, Oxford: Oxford University Press, 2011.

ZAFFARONI, Eugenio; ALAGIA, Alejandro y SLOKAR, Alejandro, Derecho penal. Parte General, Buenos Aires: Ediar, 2000.

\section{Legislación y Jurisprudencia citada}

Appeals Chamber Decision on Preliminary motion on the invalidity of the agreement between the United Nations and the Government of Sierra Leone on the establishment of the Special Court), SCSL-2004-15-AR72 (E), Prosecutor v. Augustine Gbao (2004): Corte Especial Para Sierra Leona, 25 de mayo de 2004.

Ley 975 de Justicia y Paz, Diario Oficial de la República de Colombia, No. 45.980 de 25 de julio de 2005 artículos 10, 11 y 29.

Sentencia de fondo, reparaciones y costas), Serie C. Núm. 162, La Cantuta c. Peru, Corte Interamericana De Derechos Humanos, 29 de noviembre de 2006

Sentencia Barcelona Traction Light and Power Company Limited. Sentencia, s.1. : Corte Internacional De Justicia, 5 de febrero de 1970. 
Polít. crim. Vol. 12, No 23 (Julio 2017), Art. 3, pp. 78-102.

[http://www.politicacriminal.cl/Vol_12/n_23/Vol12N23A3.pdf]

Sentencia Caso concerniente a Timor del Este, Portugal c. Australia, s.l.: Corte Internacional De Justicia, 30 de junio de 1995.

Sentencia caso relativo a las Inmunidades Jurisdiccionales del Estado, Alemania c. Italia; Grecia interviniente, Corte Internacional De Justicia, 3 de febrero de 2012.

Sentencia caso Yerodia, República Democrática del Congo c. Belgica, Corte Internacional De Justicia, 14 de febrero de 2002.

Sentencia de apelación. IT-94-1-A, Prosecutor v. Dusko Tadic, Tribunal Internacional Penal Para La Ex Yugoslavia, 15 de julio de 1999.

Sentencia de excepciones preliminares, fondo, reparaciones y costas), Serie C. Núm. 154, Almonacid Arellano y otros c. Chile, Corte Interamericana De Derechos Humanos 26 de septiembre de 2006.

Sentencia de fondo, reparaciones y costas Penal Miguel Castro Castro c. Perú, Corte Interamericana De Derechos Humanos, 25 de noviembre de 2006.

Sentencia Military and Paramilitary Activities in and against Nicaragua, s.l.: Corte Internacional De Justicia, 27 de junio de 1986.

Sentencia Sala de priemra instancia. IT-96-23-T \& IT-96-23/1-T, Prosecutor v. Dragoljub Kunarac. Radomir Kovac and Zoran Vokovic, Tribunal Internacional Penal Para La Ex Yugoslavia, 22 de febrero de 2001.

Sentencia Sala de Primera Instancia. IT-95-/7/1-T, Prosecutor v. Anto Furundzija, Tribunal Internacional Penal Para La Ex Yugoslavia, 10 de diciembre de 1998.

Sentencia Sala de primera Instancia. IT-95-16-T, Prosecutor v. Zoran Kupreskic. Mirjan Kupreskic. Vlatko Kupreskic and Drogan Papic, Tribunal Internacional Penal Para La Ex Yugoslavia 14 de enero de 2000.

Sentencia Sala de Primera instancia. IT-96-21-T, Prosecutor v. Zejnil Delalic. Zdravko Mucic. Hazim Delic and Esad Landzo, Tribunal Internacional Penal Para La Ex Yugoslavia 16 de noviembre de 1998. 